\title{
Projetos de educação ambiental em escolas: a necessidade da sistematização para superar a informalidade e o improviso
}

\author{
Zara Faria Sobrinha Guimarães ${ }^{1}$ \\ Wildson Luiz Pereira dos Santos ${ }^{2}$ \\ Patrícia Fernandes Lootens Machado ${ }^{3}$ \\ Joice de Aguiar Baptista ${ }^{4}$
}

Resumo: Este artigo apresenta dados quantitativos e qualitativos de estudos exploratórios em escolas da rede pública do Distrito Federal relativos a projetos de educação ambiental (EA) e tem como objetivo identificar a sistematização e continuidade desses projetos, a participação da comunidade escolar nos mesmos $e$ as dificuldades no seu desenvolvimento. Os dados foram coletados por meio de contato eletrônico, reuniões com professores e visitas às escolas e foram categorizados no processo analítico. Os resultados indicam que a maioria dos projetos investigados não tem continuidade, foi desenvolvida de maneira isolada, com pouca sistematização e participação de professores. Entre as dificuldades apontadas pelos professores destaca-se a falta de apoio e de recursos para os projetos. A investigação sinalizou a necessidade de organização das escolas de forma a permitir uma dinâmica de trabalho interdisciplinar por meio da qual ações de EA sejam inseridas no projeto político-pedagógico de cada escola, em processo de construção coletiva assumido de maneira continuada pela comunidade escolar.

Palavras-chave: Projeto de educação ambiental. Interdisciplinaridade.

${ }^{1}$ Doutoranda do Programa de Pós-Graduação em Educação da UnB e professora do Instituto de Ciências Biológicas da Universidade de Brasilia(UnB), Brasília, Brasil, zara@unb.br.

2 Doutor em Educação e professor do Instituto de Química da UnB e dos Programas de Pós-Graduação em Ensino de Ciências e em Educação da Universidade de Brasilia(UnB), Brasília, Brasil, , wildson@unb.br

${ }^{3}$ Doutora em Química e professora do Instituto de Química da UnB e do Programa de Pós-Graduação em Ensino de Ciências da Universidade de Brasilia(UnB), Brasília, Brasil,plootens@unb.br

${ }^{4}$ Doutora em Química e professora do Instituto de Química da UnB e do Programa de

Pós-Graduação em Ensino de Ciências da Universidade de Brasilia(UnB), Brasília,

Brasil, joice@unb.br 


\section{Environmental education projects in schools: the need for systematization in order to overcome informality and improvisation}

Abstract: This paper presents quantitative and qualitative data related to environmental education (EA) projects and taken from exploratory studies conducted in public schools in Brazil's Federal District. The aim is to identify the systematization and continuity of those projects, the school community participation in them, and the difficulties involved in their development. The results show that most of the investigated projects lack continuity, being developed in an isolated manner, with poor systematization and little involvement from teachers. Among the difficulties indicated by the teachers themselves, the lack of support and resources for the projects stands out. The research indicated the need to organize schools so as to provide an interdisciplinary work dynamics whereby EE actions can be included in the political pedagogical project of each school, establishing a collective and continuous construction process involving all the school community.

Keywords: Environmental education project. Interdisciplinarity.

\section{Proyectos de educación ambiental en escuelas: la necesidad de la sistematización para superar la informalidad y el improviso}

Resumen: Este artículo presenta datos cuantitativos y cualitativos de estudios exploratorios en escuelas de la red pública del Distrito Federal relativos a proyectos de educación ambiental (EA) y tiene como objetivo identificar la sistematización y continuidad de estos proyectos, la participación de la comunidad escolar en los mismos y las dificultades en su desenvolvimiento. Los datos se colectaron por medio de contacto electrónico, reuniones con profesores y visitas a las escuelas y se categorizaron en el proceso analítico. Los resultados indican que la mayoría de los proyectos investigados no tiene continuidad, que se desarrolló de manera aislada, con poca sistematización y participación de profesores. Entre las dificultades apuntadas por los profesores se destaca la falta de apoyo y de recursos para los proyectos. La investigación señaló la necesidad de organización de las escuelas de forma que permita una dinámica de trabajo interdisciplinar por medio de la cual se insieran acciones de EA en el proyecto político-pedagógico de cada escuela, en proceso de construcción colectiva asumido de manera continuada por la comunidad escolar. 
Palabras clave: Proyecto de educación ambiental. Interdisciplinariedad.

\section{Introdução}

A educação ambiental (EA), que vem ganhando espaço no ambiente escolar, sobrevém da mais variada forma em seu interior. Contempla, entre outras práticas pedagógicas, a idealização e execução de projetos interdisciplinares de ensino cujas propostas apresentam a busca de diferentes olhares sobre o tema, objetivando ações afirmativas que propiciem aos estudantes mudanças de visão de mundo perante os problemas ambientais.

No entanto, surge a questão sobre até que ponto tais projetos ditos interdisciplinares estão avançando rumo a uma visão integradora, com transformação de valores e atitudes ambientais para a construção de uma sociedade crítica sobre os complexos fatores que causam os problemas ambientais. Sendo assim, torna-se fundamental o desenvolvimento de pesquisas que identifiquem como estão inseridos os projetos de EA nas escolas. Entender a maneira como a EA acontece nesse ambiente possibilita a compreensão de como o saber ambiental é construído no ensino formal, quais são seus impactos e aplicações na realidade vivida por alunos, professores e comunidade e quais dificuldades têm sido encontradas.

Nesse contexto, na Universidade de Brasília, concebemos um projeto de pesquisa que tem como objetivo identificar e analisar como projetos de EA são desenvolvidos nas escolas do Distrito Federal. No presente trabalho, apresentamos análise de dados construídos na pesquisa que apontam um dos problemas centrais desses projetos. A análise buscou identificar se os projetos de EA têm sido sistematizados, tido continuidade, envolvido professores de diferentes disciplinas, bem como que dificuldades os professores que os conduzem encontram em seu desenvolvimento. Os dados foram construídos a partir de estudos exploratórios desenvolvidos pela equipe de pesquisa em suas ações para identificar projetos de EA em escolas do Distrito Federal durante o ano de 2008. O grupo tinha como objetivo posterior desenvolver ações nas escolas para subsidiá-las no processo de construção coletiva de projetos de EA.

\section{O papel de projetos de EA nas escolas}

Embora o processo ambiental educativo não tenha tido gênese na escola, a crise ambiental planetária se viu refletida nela e, a partir da década de 1970, mesmo que de modo incipiente, escolas brasileiras passaram a desenvolver ações ambientais educativas. Tais ações inicialmente objetivaram, como forma de mitigação, a proteção integral do ambiente.

Em seu processo de oficialização, documentos norteadores passaram a recomendar a educação ambiental em todos os níveis de ensino, na intenção de 
formar sujeitos capacitados para o enfrentamento das questões ambientais (BRASIL, 1988, 1997, 1999, 2002).

Nesse sentido, a escola passou a ser vista como importante aliada para a execução de atividades ambientais educativas, sendo considerada desde um local de "treinamento em proteção ambiental" (LEFF, 2001, p. 205) até um espaço de instrução na busca de um "comportamento responsável com a natureza para resolução de problemas ambientais” (HUNDT, 1966 apud LEFF, 2001, p. 205).

Por mais que se reconheça o papel amestrador exercido pela escola, em sua forma de reprodução de valores e regras universais, acredita-se que a mesma tenha se tornado uma via privilegiada para a formação de relações sociais mais livres, igualitárias e fraternas (GUIMARÃES, 1999). Dessa forma, atividades ambientais educativas escolarizadas, ainda que consideradas incipientes, têm se apresentado como práxis importante de contribuição à causa ambiental.

Veiga, Amorim e Blanco Cossío (2005) investigaram quais ações ambientais educativas as escolas públicas brasileiras de ensino fundamental praticam. Essa pesquisa revelou que durante os anos 1990 houve uma acelerada expansão de acesso à EA em um curto período. A pesquisa também detectou que projetos interdisciplinares consistiam em uma das estratégias pedagógicas mais utilizadas para a inserção da educação ambiental na escola.

Presume-se, pela análise, que a maior aspiração de tais propostas interdisciplinares é que a educação ambiental possa subsidiar a compreensão dos problemas socioambientais numa ampla relação entre natureza, sociedade, cultura e saberes escolarizados. Contraditoriamente ao exposto, Guimarães (2004) evidencia que projetos sobre educação ambiental nas escolas "tendem a reproduzir práticas restritas às salas de aula voltadas para mudanças comportamentais individuais descontextualizadas da realidade em que a escola está inserida" (GUIMARÃES, 2004, p. 31).

No entendimento de Silva e Gomes (2008), estudos sobre a forma mais adequada de inserção da EA na escola oscilam entre o uso de novas propostas curriculares e sua inserção por meio de projetos interdisciplinares, buscando-se contemplar, com eles, a complexidade de seu estudo não conseguida quando desenvolvida por disciplinas isoladas. A diversidade de proposições evidenciada faz com que as ações ambientais educativas escolarizadas apresentem um leque de abordagens orientadas por propostas pedagógicas variadas.

Tozoni-Reis (2007) polarizou as práticas pedagógicas em duas abordagens: a adaptador-reprodutora e a transformadora. A primeira busca a adaptação dos indivíduos à sociedade e culmina em reproduzir acriticamente as relações entre si e com o ambiente. A segunda promove a compreensão, de forma reflexiva e analítica, das relações sociais e ambientais da sociedade moderna.

A mesma autora categorizou um gradiente com diversas práticas pedagógicas que, orientadas para mudanças comportamentais (disciplinatóriomoralistas), sensibilização pela natureza (ingênuo-imobilistas), ativismo ambientalista 
(ativista-imediatistas) ou transmissão de conteúdos técnico-científicos (conteudistaracionalistas), raramente atingem uma perspectiva crítico-transformadora (TOZONIREIS, 2008).

A escola, ao assumir a tarefa ambiental educativa, respaldada nas legislações sobre o tema, apregoou sua inserção formal de maneira transversal e interdisciplinar, objetivando, com isso, a geração de espaço de formação de uma sociedade menos impactante em suas ações para com o ambiente. Dessa forma, fica claro que os conteúdos de tais propostas sempre buscaram minimizar os efeitos da fragmentação do conhecimento imposto pela organização curricular da escola, fomentando nessa tentativa que a comunidade escolar adquira uma postura crítica em relação aos princípios de uso da natureza pela humanidade. Por esse ângulo, os projetos interdisciplinares seriam considerados metodologias relevantes para a compreensão da questão ambiental em sua complexidade, embora, por si sós, não ofereçam garantia de transformação social.

O espaço ambiental educativo escolarizado serviu e ainda serve de sítio de penetração de várias formações especialistas e de suas diferentes visões de mundo. Os educadores ambientais têm, nos projetos interdisciplinares, a expectativa de mudança de todo o processo de formação de sujeitos capazes de interferência social. Na prática, observou-se que a proposta interdisciplinar foi entendida por diversas ações pedagógicas que dependem muito da concepção dos atores envolvidos sem, contudo, conseguir romper com as formas tradicionais de ensino tecnicistas e repassadoras de conteúdos específicos de cada disciplina.

Nesse sentido, cotidianamente a educação ambiental vem sendo consolidada como atividade educativa de cunho predominantemente naturalista, descontextualizada e isolada, ou seja, de forma muito semelhante à sua gênese no ambiente escolar.

Ressalta-se ainda que a escola, estruturada para a manutenção e reprodução de uma cultura exploratória, comum na sociedade capitalista, forçou que a EA assumisse no espaço formal uma posição paradoxal: buscar a formação de uma sociedade cidadã com atitudes de consumo e gerência do meio menos impactantes e criticar a atual forma de produção e consumo da sociedade. Assim, a escola, ao incorporar a educação ambiental, passou a desempenhar também papéis paradoxais, pois, além de ter de ajustar o indivíduo à sociedade, teve de instrumentalizá-lo para sua crítica (LIMA, 1984).

A vertente ambiental educativa acolhida pela escola exigiu dela profundos ajustes, voltados sobretudo à incorporação de metodologias diferenciadas em seu fazer educativo. Isso implicou que ações de EA não fossem meramente prescritivas, indicando apenas o que fazer para preservar o ambiente, mas geradoras de ações de reflexão sobre as forças ideológicas presentes na sociedade, veiculadas no processo educativo tradicional. 
Em sua práxis, a EA no âmbito escolar teve possibilidades de englobar desde ações restritas - que Grün (1996) assinalou como naturalistas, envolvendo apenas aspectos biológicos - como também ações realistas ou emancipadoras que incorporam componentes sociais, políticos e econômicos transformadores, por meio de ações contextualizadas à realidade na qual as escolas estão inseridas.

Entretanto, o caráter transformador/emancipador da EA, apesar de ser identificado por diversos autores (CARVALHO, 2004; GUIMARÃES, 2004; LAYRARGUES, 2002; SAUVÉ, 2005), pouco tem logrado na busca de um novo modelo de sociedade, no qual a temática ambiental seja vista de forma comprometida com a emancipação e equidade social. Nessa vertente, a EA representa a contraposição ao modelo fragmentado e dominante da sociedade atual e a separação entre ela e natureza.

Observa-se que o processo ambiental educativo, que deveria ser emancipatório em essência, tem cedido lugar a um fazer pedagógico prescritivo, comportamental e individual, classificado por Lima (2002) como conservador on comportamentalista e que pouco tem refletido a respeito das contradições sociais existentes. Deve-se considerar, no entanto, conforme afirma Medina (2000), que não se pode negar a importância de ações de EA conservadora na escola, pois, mesmo que não sejam suficientes, são tidas como necessárias para a busca de conhecimentos e valores capazes de propiciar a reestruturação social.

Por outro lado, ressalta-se que o ensino escolar, atualmente organizado em planejamentos pedagógicos hierarquizados, imóveis e desvinculados da realidade social, teria de adequar-se para alcançar seu objetivo transformador.

Silva e Gomes (2008) destacam que, ao longo da história da escolarização, a organização curricular por disciplinas tem sido amplamente aceita apesar de sofrer críticas em relação à sua incapacidade de dar conta das problemáticas sociais. Os autores sugerem como alternativa aos mecanismos disciplinares a construção de saberes interdisciplinares via componentes curriculares tradicionais na forma de projetos.

Sendo assim, seriam necessárias mudanças na instituição escolar para que se pudessem minimizar os efeitos causados pela fragmentação do saber e pela falta de integração entre os diferentes saberes científicos, os quais são todos considerados importantes para a compreensão da questão ambiental.

A necessária visão globalizante e complexa da EA implica que, para ser incorporada pela escola, ela teria de perpassar diversos componentes curriculares de maneira contínua, não sendo vista pelo olhar de uma única disciplina.

Ocorre, contudo, que o que se tem constatado em geral é que a EA escolarizada tem se processado "de modo pontual (datas ecológicas, palestras etc.), de forma fragmentada, conteudista, com pequeno envolvimento comunitário" (GUERRA; GUIMARÃES, 2007, p. 158). Em outras palavras, o que se tem observado é que a escolarização da vertente ambiental vem seguindo caminhos incertos de atividades pontuais que nem sempre são sistematizadas. 
Vários autores (BIANCHETTI; JANTSCH, 2000; FAZENDA, 1996; JAPIASSU, 1976; LUCK, 1994), na busca da superação de tal fragmentação, sugerem a abordagem interdisciplinar da EA para que se possa engajar a escola e a sociedade em trabalhos conjuntos. Tavares (1996) defende que a interdisciplinaridade deve ser compreendida como sugere María de los Dolores: "desprovendo-se do conceito absoluto da palavra disciplina e resgatando o conceito da palavra inter". Ainda na opinião de Tavares (1996, p. 34),

[...] não há interdisciplinaridade se não há intenção consciente, clara e objetiva por parte daqueles que a praticam. Não havendo intenção de um projeto, podemos até dialogar, interrelacionar [sic] e integrar sem, no entanto, estarmos trabalhando interdisciplinarmente.

Deve-se considerar, contudo, que a abordagem ambiental educativa na escola não poderá ser reduzida a apenas tal prática pedagógica. A EA “deve ser entendida principalmente como o produto do diálogo permanente entre concepções sobre o conhecimento, a aprendizagem, o ensino, a sociedade e o ambiente" (JACOBI, 2004, p. 33).

Complementando a análise de Jacobi (2004), Leff (2007) sinaliza o perigo de se considerar a interdisciplinaridade como método ou prática de produção de conhecimentos na busca da integração operativa e da resolução de problemas complexos da questão ambiental. O autor preocupa-se quando isso ocorre sem que se expressem, consistentemente, os interesses de grupos em conflito ou que se tente neutralizá-los de maneira a não reconhecer e integrar as vertentes políticas, sociais e econômicas às suas ações.

Para Leff (2007), as experiências interdisciplinares, apesar de mostrarem benefícios, podem ocultar dificuldades de diálogo entre especialistas, professores, áreas, entre outros, dando-lhes caráter superficial e, consequentemente, conservador.

$\mathrm{Na}$ busca de sua sistematização seria recomendável que os projetos se voltassem para a inserção de ações ambientais educativas no projeto políticopedagógico da escola. No entanto, Santos (2008) afirma que também seria preciso compreender como os professores organizam suas propostas de ensino em perspectivas tanto disciplinares quanto interdisciplinares.

Vários autores têm demonstrado que uma possibilidade de interdisciplinaridade na EA seriam projetos sobre o tema na escola. $\mathrm{Na}$ visão desses autores seria recomendável que os projetos interdisciplinares contemplassem o envolvimento e cooperação entre as comunidades intra e extraescolar (por exemplo, CARVALHO, 2008; GUIMARÃES, 2004; HARTMANN, 2007; LOUREIRO, 2006). No entanto, Veiga, Amorim e Blanco Cossío (2005) vão mais longe quando afirmam que tais projetos deveriam não só 
envolver as comunidades intra e extraescolar, mas também criar "canais de comunicação com a população para incrementar a discussão e reflexão sobre o papel dos cidadãos em relação ao ambiente" (VEIGA; AMORIM; BLANCO COSSÍO, 2005, p. 21).

Muito embora se concorde que projetos de EA nas escolas sejam concebidos por uma abordagem genérica e de forma desvinculada de seus projetos educativos (BRASIL, 2002), percebe-se que temas ambientais propiciam maior envolvimento escolar quando permitem a explanação de diferentes pontos de vista dos atores envolvidos. Tal fato poderia propiciar uma visão mais complexa da realidade, oportunizando ações dirigidas "para além das salas de aula" (GUIMARÃES, 2004, p. 32).

Hartmann (2007), em sua investigação sobre como a interdisciplinaridade acontece nas escolas de ensino médio do Distrito Federal, sinaliza o fato de os professores participantes da pesquisa aceitarem bem as iniciativas de realização de atividades interdisciplinares.

Apesar das dificuldades para encontrar elos entre os objetos de conhecimento, os docentes percebem um ganho de tempo e de conhecimento ao trabalhar[em] integradamente. A interdisciplinaridade, mesmo sendo um desafio, apresenta-se como uma oportunidade de desenvolvimento cognitivo, interpessoal e pedagógico. (HARTMANN, 2007, p. 204).

Diante do exposto, entende-se que projetos interdisciplinares desenvolvidos nas escolas apresentam uma boa aceitação pelos atores sociais envolvidos, embora fiquem evidentes suas múltiplas interpretações e práticas. Salientar a grande possibilidade de se tornarem propostas pedagógicas de educação ambiental partícipes na construção social de conhecimentos não nos parece inócuo. No entanto, tais projetos poderiam, em nosso entendimento, atender a formação não somente de um sujeito reintegrado à natureza mas de uma sociedade que, emancipada, seja capaz de decidir e de participar de forma crítica e igualitária em sua realidade.

Perceber como as propostas interdisciplinares acontecem nas escolas subsidia-nos possibilidades de formação e trabalho conjunto com esse segmento da educação para que possamos alcançar tal objetivo.

\section{Procedimentos metodológicos}

As instituições públicas de ensino do Distrito Federal se encontram vinculadas pedagógica e administrativamente a quatorze Diretorias Regionais de Ensino (DREs), nas quais estão distribuídas 620 instituições (533 urbanas e 87 rurais).

Buscando conhecimento a respeito dos projetos de EA nas escolas do Distrito Federal, o grupo de pesquisadores realizou duas investigações exploratórias: a primeira com os professores cadastrados no Catálogo da Rede de 
Educadores Ambientais do Distrito Federal (Redea) e a segunda com os projetos desenvolvidos nas escolas vinculadas a duas DREs.

O catálogo da Redea foi distribuído em 2007 pela Escola da Natureza, instituição vinculada à Secretaria de Estado de Educação do Distrito Federal. Tal instituição fornece cursos de formação continuada para educadores ambientais que atuam em escolas da Rede Pública de Ensino do DF. Nesses cursos são desenvolvidas atividades de orientação sobre a elaboração de projetos de EA.

Durante os meses de abril e maio de 2008 , pelos endereços virtuais contidos no referido catálogo, três mensagens eletrônicas foram encaminhadas aos professores da Rede Pública de Ensino. A primeira tratava da apresentação da proposta de trabalho e uma proposição de colaboração. Para aqueles professores que responderam ao primeiro contato foi enviada a segunda mensagem, solicitando que completassem um quadro de informações com o nome da escola, o título do projeto de EA que desenvolviam, o nome do coordenador do projeto e um meio de contato com o mesmo, além dos nomes dos professores participantes. No terceiro contato foram solicitadas informações sobre os objetivos e as ações ambientais desenvolvidas na escola durante o ano letivo de 2007.

A partir dos dados coletados nas comunicações virtuais, foram selecionados professores que responderam a todas as mensagens e que afirmaram que participavam em projetos de EA nas escolas nas quais lecionavam. Passou-se então para a segunda fase de investigação, cujas atividades tiveram início em duas regiões administrativas do Distrito Federal.

Duas DREs foram selecionadas pelo grupo de pesquisa e os critérios de seleção foram: maior número de professores inscritos na Redea; existência de projetos que buscavam coordenar ações ambientais educativas e manifestação de interesse de participação na proposta de investigação. As DREs selecionadas localizam-se em cidades-satélite do Distrito Federal e aqui serão denominadas DRE-1 e DRE-2.

Antes do encontro com os docentes, foram feitas quatro reuniões com os coordenadores do Núcleo de Monitoramento Pedagógico das duas DREs, os quais, em conjunto com os pesquisadores, agendaram os encontros com os professores participantes de seus núcleos.

Os convites para as reuniões foram feitos por meio de mensagem virtual e documento oficial aos representantes da Escola da Natureza e a todos os professores das duas regionais selecionadas que desenvolveram em 2007 ou que pretendiam desenvolver durante o ano de 2008 projetos de EA nas escolas onde lecionavam.

No decorrer da investigação, os professores da DRE-1 participaram de cinco reuniões juntamente com o grupo de pesquisa, com a coordenadora do Núcleo de Monitoramento de Ensino e dois membros da Escola da Natureza. Os 
docentes da DRE-2 participaram de apenas uma reunião, sendo adotada outra abordagem de ação em virtude de sua ausência na primeira reunião conjunta.

Nas reuniões, os professores fizeram relato oral de como era o projeto de EA desenvolvido em sua escola e anotaram em questionário pontos positivos e negativos que enfrentavam no projeto. Como desdobramento da primeira reunião da DRE-1 foi feito um encontro de orientação sobre como elaborar projeto de EA, tendo sido solicitado aos professores que encaminhassem os seus projetos através de uma conta na plataforma Moodle criada pelo grupo de pesquisa.

Os comentários e manifestações dos docentes foram anotados em caderno de campo e os textos por eles produzidos foram separados por categorias de abordagens similares. Salienta-se que os dados percentuais obtidos contemplam mais que uma resposta dada. A análise dos resultados foi desenvolvida a partir das informações fornecidas nas mensagens eletrônicas e nas reuniões com os professores.

\section{Discussão dos resultados}

Projetos de EA inscritos na Rede de Educadores Ambientais do DF

Das 137 mensagens eletrônicas enviadas aos professores cujos nomes estavam no Catálogo da Rede de Educadores Ambientais como agentes em projetos de EA nas escolas, dez foram encaminhadas para docentes que desenvolviam projetos em Centros de Educação (CED); 24, para professores de Centros de Ensino Médio (CEM); 95, para professores de Centros de Ensino Fundamental (CEF); seis, para Diretorias Regionais de Ensino e duas, para professores de Centros de Ensino Especial (CEE).

Do total de correspondências enviadas, vinte e três (23) voltaram após a terceira tentativa de reenvio. Dos 114 professores que receberam as correspondências, 79 não responderam a nenhuma das mensagens; 23 responderam a apenas duas mensagens, mesmo após o terceiro reencaminhamento, e apenas 12 professores responderam a todos os contatos estabelecidos.

Comparando as informações sobre os projetos que constavam no catálogo durante o ano de 2007 com aqueles elencados pelos 12 professores nas comunicações virtuais em 2008, verificou-se que cinco docentes da amostra relataram não desenvolver mais o projeto contido no catálogo. Entre esses cinco, três afirmaram ter deixado a sala de aula para a ocupação de outros cargos pedagógicos, um se aposentou e um se encontrava em licença por motivo de saúde.

Quatro professores relataram que, apesar de continuarem ministrando aulas na mesma escola, passaram a desenvolver atividades de um novo projeto de EA e 
apenas um dos docentes continuou as ações propostas no projeto contido no catálogo do ano anterior. Dois professores relataram desenvolver projeto de educação ambiental sem nominá-los, impossibilitando, dessa forma, a comparação dos dados.

Observa-se que só se conseguiu resposta conclusiva de um único professor, que continuava a desenvolver o mesmo projeto do catálogo da Redea-DF. O baixo número de respostas dos professores às diversas tentativas pode ser atribuído a diversos fatores, mas, muito provavelmente, a grande maioria pode não ter respondido devido à descontinuidade do projeto.

Apenas dois projetos indicados pelos professores apresentaram indicadores de que eram desenvolvidos de forma a envolver outros professores ou atores da comunidade escolar.

De certa forma, o que os dados obtidos nessa primeira etapa indicam é que muito provavelmente a maioria dos projetos cadastrados na Redea-DF é trabalhada de forma isolada pelos professores e não parece ter tido continuidade ao longo dos anos.

Projetos de EA das escolas das duas DREs investigadas

Os temas abordados nos projetos das escolas participantes das duas DREs elencados pelos professores estão categorizados na Tabela 1.

Tabela 1. Quantitativo dos projetos por temas e nível de ensino das escolas participantes.

\begin{tabular}{|l|c|c|c|}
\hline \multirow{2}{*}{ Tema da atividade ambiental } & \multicolumn{2}{|c|}{ Nível de escolarização } & \multirow{2}{*}{ Total } \\
\cline { 1 - 3 } $\begin{array}{c}\text { Cultivo de plantas (paisagísticas } \\
\text { edicinais) }\end{array}$ & 7 & 2 & 9 \\
\hline $\begin{array}{l}\text { Resíduos (compostagem, } \\
\text { clagem, coleta seletiva) }\end{array}$ & 2 & 1 & 3 \\
\hline Ambiente e valores & 1 & 1 & 2 \\
\hline Ecocidadania & 1 & & 1 \\
\hline Minhocário & - & 1 & 1 \\
\hline Educação ambiental e saúde & 1 & - & 1 \\
\hline EA (sem especificação) & 2 & - & 2 \\
\hline Total & $\mathbf{1 4}$ & $\mathbf{5}$ & $\mathbf{1 9}$ \\
\hline
\end{tabular}


Chama a atenção que a maioria dos projetos está concentrada em escolas do ensino fundamental $(74 \%)$ e que há predominância de temas relativos ao plantio de mudas e ao destino de resíduos sólidos. Isso evidencia uma concepção mais naturalista e restrita de EA (GRÜN, 1996), que Lima (2002) classificou como conservadora ou comportamentalista, voltada puramente à conservação do ambiente. Essa hipótese se fortalece na medida em que se constata na Tabela 1 que em apenas três temas há menção ao cidadão ou a sua formação integral. Esse dado corrobora também as palavras de Tozoni-Reis (2007) caracterizando as práticas pedagógicas orientadas para mudanças comportamentais (disciplinatório-moralista) ou para a sensibilização por questões da natureza (ingênuo-imobilista).

Acredita-se que os temas ambientais escolhidos pelas escolas sirvam como pano de fundo para o desenvolvimento de ações reais que estimulem a ação ambiental educativa. Entendemos que projetos de EA, independentemente de serem considerados mais ou menos estimuladores, devem propiciar a agregação de maior número de ações interdisciplinares na escola, contribuindo, dessa forma, para maior envolvimento das comunidades intra e extraescolar. Nessa perspectiva estão sendo ampliadas nossas ações investigativas, acompanhando-se alguns projetos para se entender como, na prática, os mesmos têm alcançado os objetivos mais amplos da EA.

A seguir são apresentados dados mais específicos de cada DRE.

\section{Ações na Diretoria Regional de Ensino 1}

$\mathrm{Na}$ primeira reunião na DRE-1, além dos professores pesquisadores, da coordenadora do Núcleo de Monitoramento Pedagógico da DRE-1 e de duas representantes da Escola da Natureza, estiveram presentes 15 professores de 12 instituições de ensino. Desses, 12 ministravam aulas no ensino fundamental, um, no ensino especial, e dois, no ensino médio.

Foi solicitado a cada professor presente que completasse um quadro com informações sobre seu nome, o nome da escola em que leciona e se desenvolvem atividades ambientais educativas, o título e a duração do projeto desenvolvido na escola. Três professores relataram não saber o nome dos projetos que envolviam o assunto ambiental em sua escola. Foi elencado pelos docentes presentes um total de 15 projetos de EA.

Os professores entusiasticamente relataram com detalhes as atividades desenvolvidas no projeto da escola e os atores envolvidos. Foi identificado que em cinco escolas há o desenvolvimento concomitante de projetos diferentes. Em três escolas estavam sendo desenvolvidos ao mesmo tempo dois projetos de EA e em outras duas, três projetos. O desenvolvimento de um único projeto de EA foi identificado em três instituições de ensino. Os dados fornecidos sobre os projetos permitem identificá-los claramente como de iniciativa individual de professores ou em alguns casos de um grupo muito restrito de professores. 
Esses dados evidenciam que os projetos ambientais educativos dessas escolas são fragmentados em propostas de iniciativa de cada professor individualmente, não indicando que haja uma integração com os demais professores.

Nas reuniões seguintes a média de participação ficou reduzida a 13 docentes, os quais socializaram suas experiências voltadas para a viabilização da inserção das atividades ambientais educativas nas escolas. Os participantes elencaram, na forma de pequenos textos, pontos positivos e negativos das atividades que desenvolviam e fizeram a indicação de prováveis parceiros para o desenvolvimento das ações pretendidas em atividades futuras.

Entre os pontos positivos apontados nos textos dos professores destacamse: a melhora do ambiente escolar (24,4\%); a vontade e interesse dos alunos de participar de projetos na escola (23,5\%); a troca de experiências e a existência de espaço físico na escola (18\%); a associação entre EA e o conteúdo das disciplinas que ministram $(6 \%)$ e a possibilidade de aproximação da escola com a comunidade $(6 \%)$.

Como pontos negativos ou que geram dificuldades na execução dos projetos de EA nas escolas, merecem destaque: a falta de cooperação dos colegas e diretores (25\%); a carência de material de trabalho (25\%); a ausência de apoio financeiro para a execução dos projetos (14\%); a pouca valorização profissional $(10,3 \%)$; a não sistematização dos projetos $(10,3 \%)$; a deficiência de integração entre colegas de trabalho (7\%); a ausência de formação específica (3\%); a falta de educação dos alunos (3\%) e a inconstância das ações ambientais educativas (3\%).

Ficou evidente pelas apresentações dos professores que os projetos de EA que desenvolvem nas escolas apresentam muitos pontos negativos. Apesar disso, os docentes não se sentem desmotivados para continuar o trabalho. Chama a nossa atenção o fato de a principal motivação dos projetos ser a melhoria do ambiente escolar. Considerando a precariedade física em que se encontra a maioria das escolas públicas, entende-se que provavelmente os projetos venham a atender mais a necessidade de consolidação de espaço adequado para as atividades educacionais do que necessidades mais amplas e profundas de comprometimento com todo o ambiente do planeta. No entanto, não se pode deixar de considerar que um ambiente de trabalho bem cuidado pode refletir na vida dos indivíduos envolvidos.

Percebe-se ainda que as maiores dificuldades apontadas pelos professores são a ausência de apoio da direção da escola e a falta de suporte financeiro e de recursos materiais. A não participação da direção da escola foi objeto inclusive de comentários dos professores e evidencia que os projetos são frutos de iniciativas isoladas de alguns docentes, que, por sua vez, encontram dificuldades de envolver a comunidade escolar, o que, na maioria das vezes, torna os projetos atividades pedagógicas isoladas. 
Quando os professores responderam sobre "como envolver o projeto de EA ao projeto político-pedagógico da escola", obteve-se, entre outras respostas: "é preciso contextualizar todas as ações"; "é processo como o brotar de uma semente"; "tudo depende da motivação dos idealizadores do projeto". Nota-se que em nenhuma das respostas obtidas houve proposição de ações efetivas para fazê-lo, o que evidencia que as respostas dadas pelos professores pertenciam a manifestações de ideal. Assim, ações reais de incorporação da atividade ambiental educativa ao projeto político-pedagógico escolar não haviam sido projetadas nessas atividades, parecendo existir, por parte de alguns professores, certa resistência em inserir seus projetos de EA nos projetos político-pedagógicos escolares. Isso pode ter sido motivado pela descrença no apoio dos demais colegas e do corpo diretor da instituição.

A situação percebida nos leva a acreditar que os projetos de EA desenvolvidos, muito provavelmente, tenderão a continuar isolados do contexto educacional escolarizado. Tal fato sinalizou aos pesquisadores a necessidade de auxílio, objetivando programar ações conjuntas para a promoção de medidas mais integradoras da educação ambiental nas escolas.

Quando questionados se os projetos desenvolvidos por eles nas escolas estavam formalmente escritos e entregues às coordenações/direções das escolas, obteve-se resposta afirmativa de apenas dois professores. Detectando a falta de sistematização de tais projetos, o grupo de pesquisadores propôs, durante a terceira reunião, a criação de um espaço virtual na plataforma Moodle da Universidade de Brasília (UnB). Por meio dessa plataforma, os participantes puderam contar com uma rede virtual de comunicação para dirimir suas dúvidas, discutir a implantação das atividades, socializar experiências, descobrir parceiros, compartilhar textos, entre outras ações.

Para auxiliá-los na sistematização de seus projetos, foi elaborado e apresentado um modelo de projeto baseado no já utilizado pela Escola da Natureza, o qual fora disponibilizado na plataforma Moodle. Em razão da dificuldade encontrada pelos professores na utilização da ferramenta virtual, foi realizada, no quarto encontro, uma apresentação (tour) pela plataforma Moodle e iniciou-se o cadastramento dos professores nesse ambiente virtual. Informações detalhadas sobre a elaboração de projetos foram passadas aos professores.

Uma vez cadastrados todos os docentes, foi solicitado a cada professor participante que inscrevesse seus projetos (em desenvolvimento ou a desenvolver) de acordo com o modelo sugerido e os inserisse na plataforma. Essa ação objetivou conhecer, apoiar e intervir nos projetos desenvolvidos nas escolas por meio de supervisão e orientação virtual.

Durante o período proposto para tal atividade apenas dois projetos foram inseridos na plataforma e as considerações e ajustamentos sugeridos pelos pesquisadores foram encaminhados aos professores pela rede virtual, para conhecimento e eventuais adequações. 
As respostas que tivemos às várias tentativas de obtenção dos dados dos projetos nos indicaram que na prática não havia um projeto estruturado nas escolas, havia um conjunto de ações assistemáticas, sem articulação com um projeto mais amplo. Por outro lado, o pequeno retorno e o envolvimento dos professores demonstram, de certa forma, a sua dificuldade em sistematizar ações. A percepção de nosso grupo de pesquisa sinalizava a necessidade de um processo de avaliação das ações desenvolvidas como forma de eventual readequação das atividades em curso, para o que a sistematização dos projetos poderia contribuir sobremaneira.

\section{Ações na Diretoria Regional de Ensino 2}

A reunião na DRE-2 contou com a presença de cinco docentes, quatro professores pesquisadores e duas educadoras ambientais da Escola da Natureza. Nela os professores relataram desenvolver atividades ambientais educativas em cinco escolas de ensino fundamental e em uma escola de ensino médio.

Dada a dificuldade encontrada para se agendar a reunião e a pequena mobilização dos professores dessa DRE, não houve continuidade nas reuniões. $\mathrm{O}$ que se pôde desenvolver foi a seleção, entre os projetos relatados pelos professores presentes no primeiro encontro, de uma escola para ser acompanhada por bolsista de extensão. A escola selecionada foi a que apresentou maiores evidências de envolvimento da sua comunidade interna.

Duas das professoras pesquisadoras fizeram uma visita a essa escola para estabelecer contato com a direção e os professores, oportunizando suporte pedagógico ao projeto. A aluna de graduação esteve sistematicamente na escola durante os meses de setembro a dezembro. $O$ que se pôde observar pelas informações coletadas pela bolsista foi que os projetos de EA dessa escola foram idealizados em parceria com a direção da escola, mas ainda não estavam sistematizados. Algumas atividades propostas anteriormente foram interrompidas e outras estavam somente no plano das ideias.

Em síntese, os dados obtidos da escola da DRE-2 que mais evidências apresentou de desenvolvimento de projeto de EA demonstram a dificuldade da realização de projetos de EA por toda escola, mesmo quando tais projetos são apoiados pela sua direção.

\section{Considerações finais}

As investigações exploratórias desenvolvidas apontam o caráter de isolamento das ações ambientais educativas desenvolvidas nas escolas pesquisadas, que, apesar de terem professores imbuídos na causa ambiental, têm dificuldade em sistematizar essas ações, envolver toda a escola e dar continuidade 
às mesmas. Entre as dificuldades apontadas, pode-se destacar a falta de apoio da direção da escola e a falta de recursos materiais para as ações.

Como característica evidente dessa não sistematização tem-se a fugacidade das atividades ambientais educativas, que, em sua maioria, são restritas e pontuais e, dessa forma, a EA escolarizada funciona dentro de uma perspectiva de eterno recomeço.

Os resultados da investigação ainda nos fazem defender os projetos interdisciplinares como propostas importantes para a busca de maior envolvimento da comunidade escolar em todos os seus segmentos. No entanto, a falta de sua sistematização e de sua inserção na proposta político-pedagógica das escolas os caracteriza como atividades individuais e descontextualizadas da realidade de que fazem parte.

Assim, propomos que sejam desenvolvidas ações nas escolas de forma a colaborar para que os professores possam transformar suas ações isoladas em projetos coletivos. Para isso seria importante que os projetos fossem discutidos pela comunidade escolar e sistematizados em documentos que venham a fazer parte do projeto político-pedagógico da escola. Acreditamos que essa seria uma maneira de os projetos serem construídos e assumidos coletivamente e assim propiciarem uma das condições para a sua continuidade: o compromisso coletivo.

Para a concretização de tais propostas de EA um dos obstáculos a ser vencido é a falta de apoio da direção da escola. Aqui é interessante destacar que na escola acompanhada a direção manifestava claramente o interesse em desenvolver o projeto de EA, mas o mesmo não tinha ainda sido concretizado. Ou seja, o apoio da direção é fundamental, mas não é condição única. São necessárias ações concretas de mobilização escolar que sejam sustentadas com o devido apoio financeiro daí requerido.

Ressalta-se que muitos professores desenvolvem na escola suas atribuições disciplinares e resistem às alterações sugeridas pelos documentos orientadores para a perspectiva interdisciplinar, continuando com programas estanques, enrijecidos, sem disposição de tempo para contribuir com o professor a quem coube o desenvolvimento dos projetos ambientais. Tal situação pode explicar as lamentações sobre a falta de apoio dos colegas e da administração escolar e a pouca valorização profissional, o que acaba por culminar no esvaziamento de um enfoque que poderia ser bem mais abrangente e profícuo.

Isso posto, evidencia-se que, enquanto as escolas não se reorganizarem de forma a permitir uma dinâmica de trabalho que possibilite aos professores, ainda que com seus olhares especializados, o vislumbramento de uma perspectiva interdisciplinar, provavelmente as complexas dimensões de um projeto ambiental ficarão mantidas no plano do discurso.

Deve-se destacar, sobretudo, que se percebeu um elevado grau de envolvimento dos professores no relato sobre suas atividades. Isso demonstra a 
carga emocional que projetos de EA suscitam, mobilizando professores a persistirem com tais ações apesar de todas as adversidades que enfrentam. Nesse sentido, nossas ações no momento têm sido apoiar projetos de EA de professores que entusiasticamente vêm trabalhando com o objetivo de transformá-los em projetos coletivos.

\section{Referências}

BIANCHETTI, Lucídio; JANTSCH, Ari Paulo. Interdisciplinaridade e práxis pedagógica emancipadora. Disponível em: <http://www.cce.udesc.br/titosena/> Acesso em: 03 de fev. 2009.

BRASIL. Constituição da República Federativa de 1988. Brasília: Senado Federal, 1988. Disponível em: <http://www.presidencia.gov.br>. Acesso em: 20 fev. 2009.

Secretaria de Ensino Fundamental. Parâmetros Curriculares Nacionais. Brasília: MEC/SEF, 1997. Disponível em: <http://portal.mec.gov.br/>. Acesso em: 03 fev. 2009.

. Lei no 9.795, de 27 de abril de 1999. Diário Oficial da República Federativa do Brasil, Brasília, DF, 28 abr. 1999. Disponível em: < http://www.planalto.gov.br>. Acesso em: 03 fev. 2009.

. Decreto-Lei no 4281, de 25 de junho de 2002. Diário Oficial da República Federativa do Brasil, Brasília, DF, 26 jun. 2002. Disponível em: <www.ibama.gov.br/>. Acesso em: 03 fev. 2009.

CARVALHO, Isabel Cristina de Moura. Educação ambiental crítica: nomes e endereçamentos da educação. In: LAYRARGUES, Philippe Pomier (Coord.). Identidades da educação ambiental brasileira. Brasília: Ministério do Meio Ambiente, 2004. p. 13-24.

. Educação ambiental: a formação do sujeito ecológico. São Paulo: Cortez, 2008.

FAZENDA, Ivani Catarina Arantes. (Coord.). Práticas interdisciplinares na escola. São Paulo: Cortez, 1996.

GUERRA, Antônio Fernando; GUIMARÃES, Mauro. Educação ambiental no contexto escolar: questões levantadas no GDP. Pesquisa em Educação Ambiental, v. 2, n. 1, p. 155$166,2007$.

GUIMARÃES, Mauro. Educação ambiental: no consenso um embate? São Paulo: Papirus. 2004. . A dimensão ambiental na educação. São Paulo: Papirus, 2007. 
GUIMARÃeS, Zara Faria Sobrinha. Educação Ambiental no Projeto de Assentamento Santo Idelfonso: uma experiência no Município de Novo São Joaquim, Mato Grosso. 1999. 94 f. Dissertação (Mestrado em Educação Pública) - Instituto de Educação, Universidade Federal de Mato Grosso, Mato Grosso, 1999.

GRÜN, Mauro. Ética e educação ambiental: a conexão necessária. São Paulo: Papirus, 1996.

HARTMANN, Ângela Maria. Desafios e possibilidades da interdisciplinaridade no Ensino Médio. 2007. 229 f. Dissertação (Mestrado em Educação) - Faculdade de Educação, Universidade de Brasília, Brasília, DF, 2007.

JACOBI, Pedro. Educação e meio ambiente - transformando as práticas. Revista Brasileira de Educação Ambiental, Brasília, n. 0, p. 28-35, jul. 2004.

JAPIASSU, Hilton. Interdisciplinaridade e patologia do saber. Rio de Janeiro: Imago, 1976.

LAYRARGUES, Philippe Pomier. A conjuntura da institucionalização da Política Nacional de Educação Ambiental. OLAM: Ciência e Tecnologia, v. 2, n. 1, abr. 2002. [Formato eletrônico: CD-ROM].

LEFF, Enrique. Saber ambiental: sustentabilidade, racionalidade, complexidade, poder. Petrópolis: Vozes. 2001.

LIMA, Gustavo Ferreira da Costa. Crise ambiental, educação e cidadania: os desafios da sustentabilidade emancipatória. In: LOUREIRO, Carlos Frederico Bernardo; LAYRARGUES, Philippe Pomier; CASTRO, Ronaldo de Souza (Org.). Educação ambiental: repensando o espaço da cidadania. São Paulo: Cortez, 2002. p. 1-23.

LIMA, Maria José Araújo. Ecologia humana: realidade e pesquisa. Petrópolis: Vozes, 1984.

LOUREIRO, Carlos Frederico Bernardo. Aspectos políticos e pedagógicos da educação ambiental no Brasil. Sinais Sociais, v. 1, n. 2, p. 44-83, 2006.

LUCK, Heloisa. Pedagogia interdisciplinar: fundamentos teórico-metodológicos. Petrópolis: Vozes, 1994.

MEDINA, Naná Mininni. Educação ambiental: uma metodologia participativa de formação. Petrópolis: Vozes, 2000. 231 p.

SANTOS, Akiko. Complexidade e transdisciplinaridade em educação: cinco princípios para resgatar o elo perdido. Rev. Bras. Educ., v. 13, n. 37, p. 71-83, abr. 2008.

SAUVÉ, Lucie. Uma cartografia das correntes em educação ambiental. In: SATO, Michèle; CARVALHO, Isabel Cristina de Moura. Educaşão ambiental: pesquisas e desafios. Porto Alegre: Artmed, 2005. p. 17-44. 
SILVA, Luciano Fernandes; GOMES, Maria Margarida. A pesquisa em educação ambiental no contexto escolar: contribuições para uma reflexão. Pesquisa em Educação Ambiental, v. 3, n. 1, p. 239-256, jan./jun. 2008.

TAVARES, Dirce Encarnación. Aspectos da história deste livro. In: FAZENDA, Ivani Catarina Arantes (Coord.). Práticas interdisciplinares na escola. São Paulo: Cortez, 1996. p. 2731.

TOZONI-REIS, Marília Freitas de Campos. Pesquisa-ação participativa e a educação ambiental: uma parceria construída pela identificação teórica e metodológica. In:

(Org.). Pesquisa-ação participativa em educação ambiental: reflexões teóricas. São Paulo: Annablume, FAPESP; Botucatu: Fundibio, 2007. p. 121-162.

Pesquisa-ação em Educação Ambiental. Pesquisa em Educação Ambiental, v. 3, n. 1, p. 155-169, jan./jun. 2008.

VEIGA, Alinne; AMORIM, Érica Pereira; BLANCO COSSÍO, Mauricio. Um Retrato da Presença da Educação Ambiental no Ensino Fundamental Brasileiro: o percurso de um processo acelerado de expansão. Brasília: INEP, 2005.

Artigo recebido em 02/11/2011

Artigo aprovado em 01/08/2011 